\title{
Making sense of the world's highest HIV rate
}

${ }^{66} \mathrm{I}$ 've been in Darfur, in Burma, and I couldn't believe this. It's the biggest disaster I've seen," says Elias Pavlopoulos, the head of mission for Médecins sans Frontières (MSF).

Startling words, but perhaps not surprising of a sub-Saharan African nation whose very existence, the United Nations Development Programme once said, could be threatened by the incidence of HIV within its borders.

Such is the state of affairs in the Kingdom of Swaziland, which now has the dubious distinction of having the world's highest rate of both HIV and tuberculosis (TB). About $26 \%$ of adults aged 15-49, or about 202000 of all the citizens of Africa's last absolute monarchy, are HIV-positive, according to the
Swaziland government. That number is expected to rise to 219393 within three years. HIV, of course, also leaves people open to opportunistic infections, particularly TB, so it's not altogether unexpected that the TB prevalence rate is 1275 per 100000 population. Some $83 \%$ of those are HIV-positive. To add to the misery, $7.3 \%$ of new TB cases, and $15 \%$ of retreatment cases, in 2010-11 were drug resistant ones.

Why are the 1.2 million people of this landlocked kingdom - just 200 $\mathrm{km}$ by $130 \mathrm{~km}$, or roughly the size of Wales — in such dire straits?

There is no simple answer to that question. A host of underlying factors appear to be at the root of its woes: politics, history, culture, economics, poverty, gender inequity and much more. The picture is like a 5000 piece jigsaw with hundreds of missing pieces.

The numbers are certainly striking — and harsh. There were 7114 AIDSrelated deaths in 2009. That toll is expected to rise to 8393 by 2015 . Some 70000 children have been orphaned as a result of the epidemic. National life expectancy has plummeted in a scant two decades from 61 to 40.2 years.

How is that possible in a former British protectorate that has a good road system, potable water in urban centres and an adequate health care system, featuring 13 public hospitals and health centres, as well as 186 clinics?

Normally, the system handles most basic and secondary health care needs reasonably well. But it has been in cri-

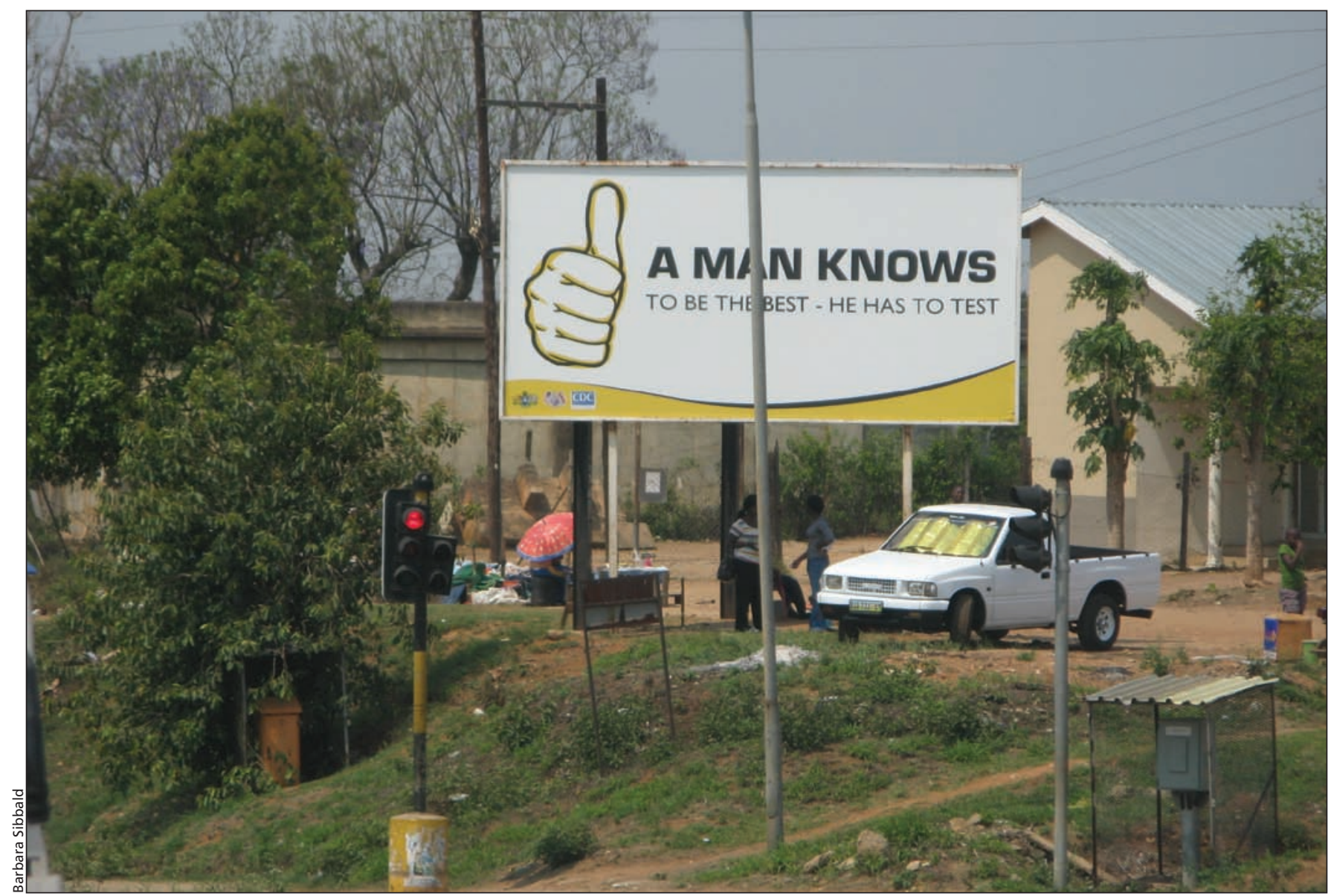

The Kingdom of Swaziland now has the dubious distinction of having the world's highest rate of both HIV and tuberculosis. 
sis since 1999. As it stands, "the situation here would be impossible for any health ministry to cope with alone," says Pieterjan Wouda, field coordinator for the MSF Shiselweni project.

The health system is definitely "fragile," according to the United Nations Development Assistance Framework. It's plagued by staffing shortages, as well as frequent shortages of laboratory supplies and antiretroviral drugs. Staff shortages are acute, with 2 physicians and 28 nurses per 10000 people (in comparison, Canada has 20 and 104). There is no medical school, although there are plans to open one in a few years, and of the 30 to 40 annual graduates from foreign medical schools, fewer than half return to practice in Swaziland. In short, vacancies for physicians and nurses abound.

When the shortage of antiretrovirals became particularly acute in 2007 , the government took the rather unusual step of inviting MSF's aid. "It was essential to intervene," says Wouda.

Today, more than 80000 people, or about $80 \%$ of those with a CD4 count of 350 cells $/ \mathrm{mm} 3$, are on antiretrovirals, which have been provided to citizens free since 2003. Since partnering with numerous nongovernmental organizations and the rapid rollout of antiretrovirals, Swaziland's HIV rates have stabilized, says Minister of Health Benedict Xabo. The emphasis now is on getting more people to testing, counseling and treatment, particularly pregnant women, "in order to ensure an HIV-free generation," adds Xabo, a nurse. Meanwhile, the percentage of pregnant women who are HIV-positive has declined to $40.5 \%$ from $42.8 \%$ in 2004.

That's a measure of progress since King Mswati III declared the HIV epidemic a national disaster in 1999.

"There was initial denial," says Dr. Velephi Okello, national coordinator for antiretrovirals with the Swaziland Ministry of Health. "We were only looking at [rates among] pregnant woman, as if pregnant women were impregnating themselves." That denial was a mistake, particularly with subtype C HIV, which is aggressive and multiplies very fast, he adds. "Within just one or two years, it can go to AIDS."
But only $30 \%$ of Swazis know their HIV status and denial remains an obstacle. "Everyone knows how it's transmitted," says Pavlopoulos. "But it's considered a treatable disease, so they don't act."

It's often been suggested that people don't want to be tested because they fear stigma and discrimination. And there's no doubt that many who do test positive hide their status from their partners and continue to have sex, typically without condoms. "New infections arise because of HIV-discordance in couples, low levels of disclosure, lack of condom use in steady couples and secret sexual partners which were not declared," stated an HIV Prevention Response and Modes of Transmission study conducted by the UN and Swaziland government (http://siteresources.worldbank.org/IN THIVAIDS/Resources/375798-11030 37153392/SwazilandMOT22March09 Final.pdf).

Part of that is attributable to the fact that Swaziland is polygamous Mswati has 14 wives - and economic hardship has led to a decline in legal marriages, especially in view of the need for men to provide their bride's family with 15 to 17 cows. Swazis favour sex with multiple partners. "Transmission is mainly $[73 \%-95 \%]$ through heterosexual contact between steady, longer-term and older partners," the study stated. "Demonstrating a man's wealth, standing and manhood is linked to his ability to secure women."

The live-birth rate is now 3.7 children per woman, and many of those offspring are not being financially supported by their biological fathers. Roughly half of the population is unemployed. About two-thirds live below the national poverty line and about a quarter rely on food aid. While Swaziland has a relatively high per capita income of US\$2415, some 56\% of the wealth is held by $20 \%$ of the population. The poorest $20 \%$ hold just $4.3 \%$ of the wealth.

The poverty has resulted in women with children often struggling to make ends meet by engaging in transactional sex for groceries or services, including many of those "lucky" enough to find work below minimum wage in the textile factories springing up in Mat- sapha. "These are normal women, like you and me," says Okello. "This is new." Not surprising then that about $62 \%$ of new infections are occurring within women.

Compounding the problem is a relatively uneducated population. While school is free until grade three, the cost of tuition, books and uniforms deters many from attending beyond that and as a consequence, $13 \%$ of adults, or about 95000 Swazis, are illiterate.

While the solutions to such problems are typically driven by government, that doesn't appear likely in Swaziland.

"The biggest problems in Swaziland are governance issues," notes Thulani Rudolf Maseko, a human rights lawyer in Mbabane.

Swaziland's legislature has 55 elected members and Mswati, who has been in power for 26 years, appoints another 25-30, as well as all ministers, judges and chiefs. Political parties are banned and dissent rapidly stifled. Although Swaziland gained its independence from Britain in 1968, within five years, then-king Sobhuza II issued a decree that repealed the constitution and consolidated all legislative, executive and judicial power in the throne. Although Mswati assumed the helm in 1986 and ratified a new constitution in 2006 , it would be a stretch to conclude that Swaziland is democratic.

Mswati's hand-picked advisory council, the Liqoqo, can veto parliamentary measures. For example, it delayed the sexual offences registry 10 years and modified it, ostensibly to reflect Swazi culture. As a result, stalking is considered a form of courting and marital rape a non sequitur. One in three Swazi women is sexually assaulted in her lifetime.

Maseko, head of a loose coalition of lawyers who voluntarily represent Swazis in human rights cases, says human rights violations, especially against women, are routine, the rule of law is ignored and opposition parties are not well organized. "The monarchy is proud of getting rid of the British, but they just took over their seat," he says. "Many in government are compromised. The country could be selfsupporting but you can't with all the 
corruption." Swaziland's finance minister told the New York Times in 2008 that about US\$5 million to US\$8 million annually is lost from public coffers because of corruption.

Resolving the HIV crisis against such a backdrop seems a monumental, if not impossible, task. But MSF, other nongovernmental partners and the Swazi health ministry have battled against that tide with initiatives such as condom distribution (although half of sexually active males engaged in non-regular sex without using con- doms); advertising and behavioural change campaigns including billboards featuring such catchy slogans as "A man knows to be the best - he has to test;" prenatal HIV testing and treatment of pregnant women in a bid to prevent mother-to-child transmission; and a circumcision campaign. The government has also collaborated with MSF to improve health services and staffing in many clinics. But whether such measures can offset the systemic deficiencies and woes is another of the missing pieces in the puzzle of the HIV epidemic in Swaziland. - Barbara Sibbald, CMAJ

CMAJ 2012. DOI:10.1503/cmaj.109-4315

Editor's note: First of a multipart series. Barbara Sibbald's accommodation and transportation while in Swaziland were provided by Médecins sans Frontières.

Next: The face of an epidemic 